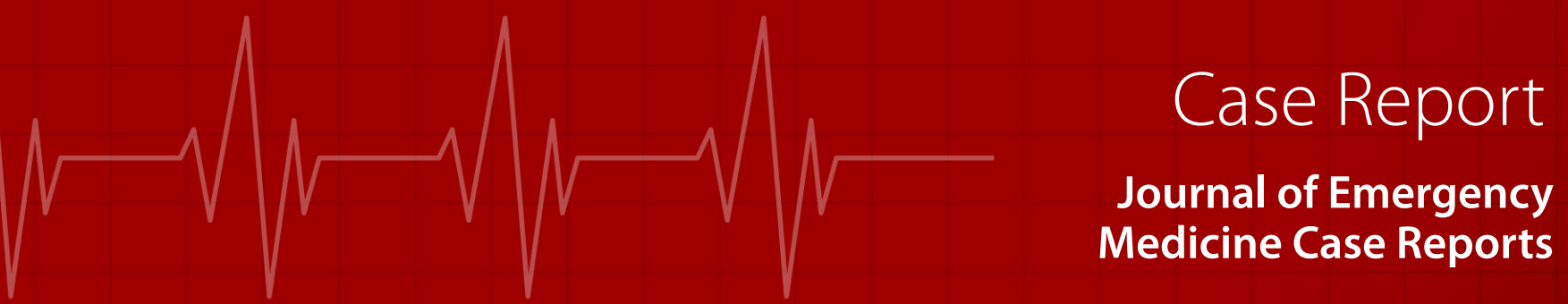

\title{
A New Risk Factor for Hepatic Encephalopathy: Ingestion of Mad Honey
}

Mustafa Yakarışık1, Cafer Akköz¹, Muhammet Ali Ayvaz², Ahmet Cumhur Dülger²

'Department of Internal Medicine, Giresun State Hospital Affiliated to Giresun University, Giresun, TURKEY

${ }^{2}$ Department of Gastroenterology, Giresun State Hospital Affiliated to Giresun University, Giresun, TURKEY

\section{Abstract}

Introduction: Hepatic encephalopathy (HE) is a neuropsychiatric syndrome that occurs in the severe liver dysfunction and is characterized by a wide range of central nervous system symptoms. Hepatic encephalopathy precipitated with mostly infections, gastrointestinal bleeding, diuretic overdose, electrolyte imbalance, constipation and drugs. Traditional local foods for example honey can contain toxins for the liver and could cause acute decompensation in patients with chronic liver disease (CLD). This toxins can cause dose related severe symptoms. Spectrum of the symptoms are from nausea, vomiting to life threatening bradycardia and/or hypotension.

Case Report: A 66-years-old man with prior hepatitis B-related Child-Pugh B cirrhosis admitted to the hospital with nausea, vomiting, confusion, gross disorientation and bizarre behavior. By the aid of medical history, physical examination, laboratory tests and imaging techniques; hepatic encephalopathy diagnosed with distinct aetiology, is mad honey consumption.

Conclusion: In this paper; we reported first time in English literature a cirrhotic case with hepatic encephalopathy due to consumption of mad honey.

Key words: Grayanotoxins (GTS), hepatic encephalopathy (HE), mad honey (MH)

\section{Introduction}

Hepatic encephalopathy (HE) is a neuropsychiatric syndrome and is characterized by a wide range of central nervous system symptoms and findings including trivial lack of awareness, euphoria, anxiety, shortened attention span, lethargy, somnolence, stupor, coma as well as dead, flapping tremor in connection with higher serum ammonia levels ${ }^{1}$.

Precipitating factors of acute HE are infections, gastrointestinal bleeding, diuretic overdose, electrolyte disorders, constipation, psychoactive drugs, dehydration and consumption of large amounts of animal protein containing foods ${ }^{2}$.

Mad honey $(\mathrm{MH})$ is a natural form of honey which obtained from forested areas of Asia and believed to beneficial to health in many parts of Asia especially in northeast part of Turkey. MH has also some toxic properties including grayanotoxins (GTS) which causes bradycardia, hypotension and agitation. Consumption of honey containing GTS obtained from Rhododendron plant species is termed as $\mathrm{MH}$ poisoning, and it is mostly reported in north east of Turkey, Korea, and $\mathrm{Nepal}^{3,4}$.

Diet management of the patient with chronic liver disease (CLD) takes an essential role in preventing HE, there is lack of studies regarding dietary advice about honey consumption for patients with cirrhosis in medical literature. We present the first case $\mathrm{HE}$ due to consumption of $\mathrm{MH}$.

\section{Case Description}

A 66-years-old man with prior hepatitis B-related ChildPugh B cirrhosis admitted to the hospital due to nausea, vomiting, confusion, gross disorientation and bizarre behavior. His wife declared that, he was consumed a large amount of $\mathrm{MH}$ due to belief in anti-cirrhotic effect before the emergency admission. He was taking lactulose, propranolol and L-ornithine L-aspartate regularly for two years. He was nonsmoker and taking no alcohol. Also his family history was not remarkable about CLD. Physical examination showed a blood pressure of 100/70 $\mathrm{mmHg}$ and a heart rate of $60 \mathrm{bpm}$, with normal respiratory and cardiac auscultation. He had a flapping tremor, with a palpable spleen $3 \mathrm{~cm}$ below the left costal margin. There were no sign of ascites and gastrointestinal bleeding. The electrocardiogram and chest X-ray were normal. His laboratory tests were as follows white blood cell count: $2.770 / \mathrm{mm}^{3}$; hemoglobin: $11,4 \mathrm{~g} / \mathrm{dl}$; platelets: $74.000 /$ $\mathrm{mm}^{3}$; alanine aminotransferase: $195 \mathrm{U} / \mathrm{L}$; aspartate aminotransferase: $335 \mathrm{U} / \mathrm{L}$; alkaline phosphatase: $229 \mathrm{U} / \mathrm{L}$, J-glutamyl transferase: $210 \mathrm{U} / \mathrm{L}$; lactate dehydrogenase: 358 $\mathrm{U} / \mathrm{L}$; total bilirubin: $1,69 \mathrm{mg} / \mathrm{dl}$; direct bilirubin: $0,6 \mathrm{mg} / \mathrm{dl}$; prothrombin time: 16.2 seconds; serum albumin: $28,9 \mathrm{~g} / \mathrm{L}$; serum creatinine: $0.9 \mathrm{mg} / \mathrm{dL}$. His plasma ammonium level was also $240 \mathrm{U} / \mathrm{L}$ (normal range; 0-80). While serology tests for Hepatitis A, C and E viruses were negative; he tested

Corresponding Author: Mustafa Yakarisik e-mail: mustafa.yakarisik@gmail.com 
positive for hepatitis B surface antigen with low levels of hepatitis B virus DNA by PCR. Thus following investigations were carried out and revealed that liver size was in $120 \mathrm{~mm}$, and had lobulated contours with increased caudate lobe. There was no solid or cystic lesion. Gallbladder had 37 $\mathrm{mm}$ in transverse diameter and its wall thickness was $3 \mathrm{~mm}$ which was in normal limits. His choledochus size was $9 \mathrm{~mm}$ which was in normal limits. Pancreas had normal contours and its parenchyma was homogeneous. Axial diameter of splenic size was $165 \mathrm{~mm}$. Additionally, portal vein doppler ultrasonography was performed and showed us: portal vein and its branches were clear, no evidence of thrombosis, both of portal and splenic veins' sizes were increased which are compatible with portal hypertension. His cranial computed tomography and magnetic resonance imaging of brain revealed no striking findings. His final diagnosis was advanced stage liver cirrhosis due to chronic hepatitis B infection with HE. He was treated with colonic cleansing with lactulose twice per day and rifaximine $1200 \mathrm{mg}$ per day orally. At the end of the second day of hospital stay, his ammonium level was reduced to $100 \mathrm{U} / \mathrm{L}$ with normalization of $\mathrm{HE}$ findings. He referred to another hospital for liver transplantation.

\section{Discussion}

We described the first case report has shown that HE may has been due to $\mathrm{MH}$ poisoning in a compensated patient with cirrhosis.

MH intoxication may occur after ingestion of the honey contaminated with lipid-soluble toxins called GTS ${ }^{5}$. GTS are mainly obtained from the nectar of Rhododendron ponticum which is a member of Ericaceae botanical family. Those plants are mostly growing on the mountains of the eastern Black Sea region of Turkey also in Japan, Nepal, Brazil and some parts of North America and Europe ${ }^{6}$.

$\mathrm{MH}$ has been used in these regions as an indigenous medicine to relief abdominal pain, arthralgia, dyspepsia and to treat gastritis, hypertension, diabetes mellitus and also used for sexual stimulating effect? ${ }^{7}$.

Symptoms of MH intoxication are dose related. Minor symptoms are including dizziness, weakness, excessive perspiration, hypersalivation, nausea, vomiting and paresthesia and close follow-up is enough. However, when severe intoxication happened, it may lead to life threatening cardiac complications such as hypotension or atrioventricular blocks ${ }^{8}$.

In our case there were no bradycardia or hypotension which is related to muscarinic effect of the mad honey. In addition there were no precipitating factors for developing HE including pulmonary and urinary tract infections, intracranial events, constipation, electrolyte disturbances, gas- trointestinal bleeding, history of alcohol consumption, use of anti-depressions and narcotic drugs. Thus we postulated that described case's clinical picture was related to $\mathrm{MH}$ poisoning.

Currently there are a few case reports involving $\mathrm{MH}$ intoxicated non-cirrhotic patients with seizures probably due to neurotoxic effects of GTS ${ }^{9,10}$. A Turkish study showed that intracerebral administration of GTS successfully stimulates convulsive generalized seizures in adult Wistar rats ${ }^{11}$.

Rat studies also revealed that M2-muscarinic receptors are involved in cardiotoxicity of GTS 6 . In addition, GTS facilitate the entry of calcium into cells by modifying action potential of sodium channels and increasing permeability of sodium ions in excitable membranes. This calcium-related effects resulted in prolonged depolarization period of the excitable cells including nerve and muscle fibers ${ }^{12}$. Thus inactivation of excitable cells are inhibited ${ }^{13}$.

GTS are lipid-soluble neurotoxins which have cardio-toxic effects via M2- muscarinic receptors. On the other hand, almost $30 \%$ of GABAergic neurons in cortical neuronal system express M2 receptors ${ }^{14}$. It has also been a well known fact that, the mechanism of HE due to hyperamoniemia is related with activity of GABAergic neurons in brain $^{15}$.

To the best of our knowledge, this is the first case report that describing $\mathrm{MH}$ poisoning causing $\mathrm{HE}$ in a patient with cirrhosis. But there is no available data about GTS' capability of passing the blood brain barrier. There is also need further studies in the field of neurophysiology about GABAergic effects driven by GTS.

We finally concluded that dietary management of the patient with CLD takes an essential role in preventing HE. Mad honey consumption could be a risk factor for HE in these patients. Further large scale studies are necessary to determine whether and how $\mathrm{MH}$ consumption as a risk factor for HE in the literature.

\section{Conclusion}

Mad honey consumption is the first reported aetiology in the literature of a common condition called hepatic encephalopathy. Clinicians should be alert on honey - mad honey consumption, before regarding hepatic encephalopathy with unknown aetiology.

\section{Ethics}

The authors have no ethical conflicts to disclose. Written informed consent to publish the case report was obtained from the patient. 


\section{References}

1. Wijdicks EF. Hepatic Encephalopathy. N Engl J Med. 2016 Oct 27;375(17):1660-1670.

2. Weissenborn K. Hepatic Encephalopathy: Definition, Clinical Grading and Diagnostic Principles. Drugs. 2019 Feb;79 (Suppl 1):5-9.

3. Huseyin Sahin, Emine Akyuz Turumtay, Oktay Yildiz \& Sevgi Kolayli Grayanotoxin-III Detection and Antioxidant Activity of Mad Honey, International Journal of Food Properties. 2015 18:12, 2665-2674.

4. M. Bostan, H. Bostan, A. O. Kaya et al. Clinical events in mad honey poisoning: a single centre experience. Bulletin of Environmental Contamination and Toxicology, vol. 84, no. 1, pp. 19-22, 2010.

5. Cestèle $S$, Catterall WA. Molecular mechanisms of neurotoxin action on voltage-gated sodium channels. Biochimie. 2000 Sep-Oct;82(9-10):883-92.

6. Onat FY, Yegen BC, Lawrence R, Oktay A, Oktay S. Mad honey poisoning in man and rat. Rev Environ Health. 1991;9(1):3-9.

7. Silici S, Atayoglu AT. Mad honey intoxication: A systematic review on the 1199 cases. Food Chem Toxicol. 2015 Dec;86:28290.

8. Koca I, Koca AF. Poisoning by mad honey: a brief review. Food Chem Toxicol. 2007 Aug;45(8):1315-8.
9. Poon $W T$, Ho $C H$, Yip $K L$, Lai $C K$, Cheung $K L$, Sung $R Y$, et al. Grayanotoxin poisoning from Rhododendron simsii in an infant. Hong Kong Med J. 2008;14(5):405-407.

10. Dilber E, Kalyoncu M, Yarıs, N, Ökten A. A case of mad honey poisoning presenting with convulsion: intoxication instead of alternative therapy. Turk J Med Sci 2002;32:361-362X.

11. Kuru P, Torun $M$, Halac HM, Temiz G, Iskender $E$, Karamahmutoglu $T$, et al. Electroencephalographic and behavioral effects of intracerebroventricular or intraperitoneal injections of toxic honey extract in adult Wistar rats and GAERS. Neurol Sci. 2014 Dec;35(12):1903-8.

12. Doğanyiğit $Z$, Silici $S$, Demirtaş $A$, Kaya E, Kaymak E. Determination of histological, immunohistochemical and biochemical effects of acute and chronic grayanotoxin III administration in different doses in rats. Environ Sci Pollut Res Int. 2019 Jan;26(2):1323-1335.

13. Gunduz, S. Turedi, H. Uzun, and M. Topbas. Mad honey poisoning. American Journal of Emergency Medicine, vol. 24, no. 5.

14. Disney AA, Aoki C. Muscarinic acetylcholine receptors in macaque $\mathrm{V} 1$ are most frequently expressed by parvalbumin-immunoreactive neurons. J Comp Neurol 2008;507:1748-1762.

15. Olga A. Sergeeva, GABAergic transmission in hepatic encephalopathy, Archives of Biochemistry and Biophysics, Volume 536, Issue 2, 2013, Pages 122-130. 